Revue internationale de l'économie sociale

Recma

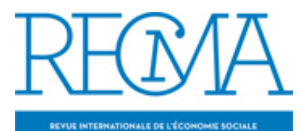

\title{
L’économie sociale en mouvement
}

\section{Jean-François Draperi}

Numéro 294, novembre 2004

URI : https://id.erudit.org/iderudit/1022016ar

DOI : https://doi.org/10.7202/1022016ar

Aller au sommaire du numéro

Éditeur(s)

Institut de l'économie sociale (IES)

ISSN

1626-1682 (imprimé)

2261-2599 (numérique)

Découvrir la revue

Citer ce document

Draperi, J.-F. (2004). L'économie sociale en mouvement. Revue internationale de l'économie sociale, (294), 4-4. https://doi.org/10.7202/1022016ar d'utilisation que vous pouvez consulter en ligne.

https://apropos.erudit.org/fr/usagers/politique-dutilisation/ 


\section{L'ÉCONOMIE SOCIALE EN MOUVEMENT}

'économie sociale est en mouvement. Qui en doute encore? Elle semble s'être plus transformée pendant les cinq dernières années qu'au cours des vingt précédentes.

Des années 70 à la fin du XXe siècle, les débats étaient dominés par les problèmes liés à la concurrence accrue à laquelle devaient faire face les entreprises d'économie sociale et par ceux liés au désengagement de l'Etat. L'intégration économique et l'instrumentalisation politique s'accompagnaient d'une accélération des processus de banalisation, d'une crise identitaire, d'un déficit de la participation sociétaire, de la mise en question des modèles théoriques classiques. Lorsque les analyses soulignaient le dynamisme de la créativité associative, elles mettaient plus volontiers l'accent sur les nouvelles fonctions remplies par les associations que sur un renouvellement de l'économie sociale, dont l'unité ne paraissait pas assurée, en France comme en Europe. Le volontarisme marqué dont faisait preuve une poignée de militants acteurs et chercheurs de l'économie sociale pour refonder l'économie sociale et la sortir de son isolement ne suffisait pas à compenser ce mouvement de fond.

Depuis quelques années, ces questions défensives ont pris un coup de vieux, et c'est tant mieux! L'économie sociale se mesure avec le compte satellite présenté par Edith Archambault et Philippe Kaminski, elle s'évalue avec le bilan sociétal mis en œuvre à la MSA (Brigitte Riberolles), promeut de nouveaux métiers (Cécile Clergeau et Annie Dussuet), se ressource avec l'épargne solidaire (Pascal Glémain), se renouvelle par la participation des jeunes à la vie associative (Valérie Becquet) et se refonde en repensant son histoire (Dominique Marshall). Dans un contexte économique, social et politique difficile, l'économie sociale retrouve ses valeurs et les voies de réalisation de sa mission historique: répondre par anticipation et par l'innovation aux attentes non satisfaites de la population.

Jean-François Draperi 